\title{
Identification of novel hypoxia-responsive factors in deep-water rice conferring tolerance to flood during germination
}

\author{
D. KUMAR ${ }^{1,3 *}$, P.K. DAS ${ }^{1,2}$, and B.K. SARMAH ${ }^{2}$ \\ Department of Agricultural Biotechnology, Assam Agricultural University Jorhat-785013, India \\ DBT-AAU Centre, Assam Agricultural University Jorhat-785013, India ${ }^{2}$ \\ Swedish university of Agricultural Sciences, SE-23053 Alnarp, Sweden ${ }^{3}$
}

\begin{abstract}
Flood in rice fields at the time of seed sowing and early seedling establishment causes extensive crop loss due to the inability of the seeds to tolerate and overcome submergence. In the present study, rice genotypes from Assam, India tolerant to hypoxia during germination were identified through systematic screening of deep-water rice genotype collection from flood-prone ecosystem of Brahmaputra river valley. The difference in tolerance to hypoxia during germination within the species provides scope for identification of novel hypoxia-responsive factors involved in tolerance as mechanism of tolerance may not be conserved across tolerant germplasms. Tolerant genotypes were further subjected to physiological and molecular characterization. Growth rate kinetics in tolerant genotypes new Rangdhakekua bao (RKB) and cultivar Khao Hlan On (KHO) from International Rice Research Institute (IRRI) used as positive control exhibited stronger escape strategy under hypoxic condition compared to sensitive genotype IR-64 (negative control). Activities of $\alpha$-amylase and pyruvate decarboxylase were significantly higher in RKB and KHO than in IR-64, while no significant difference was observed in the alcohol dehydrogenase activity. Reverse transcription quantitative PCR confirmed increased amounts of transcripts of sucrose nonfermenting 1 related protein kinase, myeloblastosis-related protein S1, rice amylase 3D, and trehalose phosphate phosphatase 7 genes, which are known to be involved in hypoxia signaling cascade. Besides, transcription factors (TFs) like ethylene responce factors 71 and 63, ethylene insensitive 3-like 1a and proteins like expansins A7 and A2, which are involved in cell elongation had also significantly higher amounts in RKB compared to IR64. Additional factors that include TFs like ERF71 and ERF63 that shows perturbation at transcription even within tolerant genotypes might constitute the genotype-specific regulation, evolved as a part of its adaptive mechanism to survive under submerged conditions.
\end{abstract}

Additional key words: $\alpha$-amylase; anaerobic germination, Oryza sativa, pyruvate decarboxylase, transcription factors.

\section{Introduction}

Among cereals, rice could withstand partial submergence and water-logging due to the presence of aerenchyma system that facilitates aeration. However, flood after sowing and during early seedling emergence causes severe crop loss (Setter et al. 1997, Jackson and Ram 2003). This problem undermines the advantage of the adoption of direct seeded technique (Tuong et al. 2000, Coumou and Rahmstorf 2012). Several genotypes exhibiting a different tolerance to anaerobic condition during germination have been identified through screening and incorporated in the breeding programme (Septiningsih et al. 2013). Physiological and biochemical studies over the years have led to the elucidation of traits that are associated with flood tolerance during germination (Ismail et al. 2009, Angaji et al. 2010, Ella et al. 2010, 2011, Septiningsih et al. 2013). Germination of tolerant genotypes is characterized by high starch mobilization and coleoptile elongation rate, a strategy that has been adopted to get faster access to oxygen when reaching the water surface (Ismail et al. 2009). This strategy primarily involves

Submitted 7 February 2019, last revision 3 October 2019, accepted 22 October 2019.

Abbreviations: ADH - alcohol dehydrogenase; CIPK15 - calcineurinB-like protein-like protein kinase 15; DAS - days after sowing; ERF - ethylene response factor; HSD - honestly significant difference; KHO - Khao Hlan On; MES - 2-[N -morpholino]- ethane-sulphonic acid; PCA - principal component analysis; PDC - pyruvate decarboxylase; QTL - quantitative trait locus; Ramy3D - rice amylase 3D; RKB - Rangdhakekua bao; RT-qPCR - reverse transcription quantitative PCR; SnRK1A - sucrose nonfermenting 1 related protein kinase; TPP7 - trehalose phosphate phosphatase 7; T6P - trehalose 6-phosphate.

Acknowledgments: This work was supported by the DBT Government of India through the DBT-AAU center (Grant No. DBT-NERagri-30-2015).

* Corresponding author; e-mail: dhananjayphdresearch@gmail.com 
a shift to fermentation from mitochondrial respiration under anaerobic condition (Bailey-Serres and Voesenek 2008, Magneschi and Perata, 2009, Mustroph et al. 2010). Starch, which constitutes $75 \%$ of cereal grain dry mass, provides the major carbon source for generating energy and metabolites during germination and seedling growth (Ella and Setter 1999, Ismail et al. 2009, Magneschi and Perata 2009). Only tolerant genotypes have great ability to utilize the starch reserve for high growth rate of the coleoptiles (Atwell and Greenway 1987, Perata et al. 1992 1993). Enzyme Ramy3D (Ismail et al. 2009) acts as a target of a sugar sensing and signaling cascade under hypoxia and its activity is regulated by the energy sensor serine/threonine kinase SnRK1A which by itself gets activated by calcineurin B-like protein kinase CIPK15, a serine /threonine kinase that processes the $\mathrm{O}_{2}$ deficiency signals that is received through calcineurinB-like protein5 (CBL5) due to perturbation in cytoplasmic calcium content (Lee et al. 2009, Kudahettige et al. 2010). Although the role of trehalose 6-phosphate (T6P) in hexokinasemediated sugar signaling and its role in saccharide homeostasis and energy signaling has been found to be due to the ability to catalytically inactivate SnRK1A in vitro (Zhang et al. 2009). The identification of trehalose phosphate phosphatase 7 (TPP7) as the underlying gene in the quantitative trait locus (QTL) qAG9-2 implicated TPP7 in relaxation of T6P mediated catalytic inactivation of SnRK1A through increased T6P turnover in tolerant genotypes (Zhang et al. 2009, Kretzschmar et al. 2015). Regulation of hypoxia-responsive downstream pathway gene under oxygen deficiency is mainly regulated by group VII of the ethylene-responsive factor (ERF) family. The Arabidopsis group VII-ERFs AtRAP2.2, AtRAP2.12, and AtRAP2.3 are constitutively expressed during oxygen deficiency and are under the control of N-end rule pathway of degradation. (Gibbs et al. 2011, Licausi et al. 2011, Weits et al. 2014). Despite knowledge regarding the molecular response to hypoxia, the actual mechanisms leading to the induction of low-oxygen-responsive genes in plants have been elusive (Fukao and Bailey-Serres 2004, Bailey-Serres and Chang 2005). The present study involving tolerant deepwater rice genotypes accessed for physiological and molecular attributes associated with germination to highlight variation in mechanism of hypoxia tolerance. Such genotype-specific regulation might have evolved as a part of its adaptive mechanism to survival under submerged condition.

\section{Materials and methods}

Deepwater rice (Oryza sativa L.) cv. Rangdhakekua bao (RKB) seeds were obtained from Regional Agricultural Research Stations, Lakhimpur and Titabar, Assam Agricultural University, Jorhat, India. The tolerant line Khao Hlan On (KHO) seeds were obtained from International Rice Research Institute (IRRI), Philippines and used as positive control and IR-64 was locally grown sensitive genotype and used as negative control. All the seeds used in the current experiment were harvested in the same season and well dried. Seeds were surface sterilized with $3 \%$ sodium hypochlorite for 4 min, washed 5 times with deionized water and placed in the bottles (40 seeds per bottle) filled with a water upto $10 \mathrm{~cm}$ and germinated in a growth chamber at a temperature of $33^{\circ} \mathrm{C}$ in the dark (Fig. 1 Suppl.). After 4 days of sowing, germinating seeds were collected and immersed in liquid $\mathrm{N}_{2}$ and stored at $-80{ }^{\circ} \mathrm{C}$ for further processing.

Seed hypoxia treatment: In order to screen for hypoxia tolerance, seeds were placed in a water tank filled with water following the procedure as essentially described by Angaji et al. (2010). Briefly, the seeds were sown about $1-1.5 \mathrm{~cm}$ below the soil surface (fine and dry soil were used, collected from the local rice field of Assam) and filled with water up to a depth of $10-12 \mathrm{~cm}$. The number of days for the coleoptiles to touch the water head surface and the growth kinetics of coleoptiles were recorded. Simultaneously, the seeds were also grown in germination trays under aerobic condition (control) to check the germination efficiency of the seeds. Eventually, after $21 \mathrm{~d}$ of sowing, seedling establishment percentage was recorded. Greenhouse average conditions were the following: 14-h photoperiod, an irradiance of $800 \mu \mathrm{mol} \mathrm{m} \mathrm{m}^{-2} \mathrm{~s}^{-1}$, day/night temperatures of $33 / 20^{\circ} \mathrm{C}$ and an air humidity between 70 and $85 \%$. Experiments were repeated 5 times and 40 seeds were measured independently each time. Trait differences were subjected to principal component analysis (PCA), one-way ANOVA, followed by the Tukey's honestly significant difference (HSD) post hoc test $(P<0.05)$. All statistical analyses were performed using statistical package XLSTAT (https://www.xlstat.com).

Alcohol dehydrogenase (ADH) assay: The reaction mixture consisted of $100 \mathrm{~mm}^{3}$ of extracts, $62.5 \mathrm{mM} \mathrm{MES}$, $0.5 \mathrm{mM}$ thiamine pyrophosphate chloride, $50 \mathrm{mM}$ oxamate, $10 \mathrm{U}$ of ADH, and $0.17 \mathrm{mM}$ NADH. To initiate the reaction, $10 \mathrm{mM}$ of pyruvate was added and the coupled NADH oxidation was monitored at $340 \mathrm{~nm}$ and $30^{\circ} \mathrm{C}$ for $10 \mathrm{~min}$. Total ADH activity was analyzed using the procedures described in Ella et al. (1993). Briefly, the $100 \mathrm{~mm}^{3}$ of crude extract, $66.67 \mathrm{~mm}^{3}$ of $3 \%(\mathrm{~m} / \mathrm{v})$ bovine serum albumin was added and samples were centrifuged at $10000 \mathrm{~g}$ for 3 min. From the supernatant, $20 \mathrm{~mm}^{3}$ of the extract was used for the reaction mixture with $51.8 \mathrm{mM} \mathrm{N}, \mathrm{N}_{,} \mathrm{N}^{\prime}, \mathrm{N}^{\prime}-$ tetraethylsulfamide and $0.17 \mathrm{mM} \mathrm{NADH}$, and the tubes were kept on ice. Acetaldehyde $\left(10.02 \mathrm{~mm}^{3}\right)$ was added and ADH activity was monitored at $340 \mathrm{~nm}$ and $30{ }^{\circ} \mathrm{C}$ for $7 \mathrm{~min}$. The Bradford method (Bradford 1976) was used for total protein assay with bovine serum albumin as a standard. Analyses were made from four independent replicates for each time-point. The assay mixture contained $0.2 \mathrm{~mm}^{3}$ of extract, 10 units of ADH in $100 \mathrm{mM}$ DTT, and, $60 \mathrm{mM}$ Na-MES, pH 6, $60 \mathrm{mM} \mathrm{Mg}^{2+}, 1 \mathrm{mM}$ TPP, $0.5 \mathrm{mM}$ $\mathrm{NADH}, 0.17 \mathrm{mM}$ oxamate, and $50 \mathrm{mM}$ pyruvate. One unit of $\mathrm{ADH}$ activity was defined as oxidation of $1 \mu \mathrm{mol}$ of NADH per minute.

Pyruvate decarboxylase (PDC) assay: Total PDC activity was analyzed using the procedure described 
by Quimio et al. (2000). Tissue was ground in a mortar with the help of pistil for 2 min in extraction buffer and acid-washed sand, with a ratio of tissue fresh mass to extraction buffer of 1:5. The extract was filtered through Miracloth and the filtrate was centrifuged at $15000 \mathrm{~g}$ for 2 min. Filtration through Miracloth was omitted if the extraction volume was lower than $2 \mathrm{~mm}^{3}$. The extract was incubated at $20{ }^{\circ} \mathrm{C}$ for $1 \mathrm{~h}$ prior to the assay. A sample of the supernatant was removed for determination of soluble protein (Lowry et al. 1951). Bovine serum albumin was added to a final concentration of $1 \%(\mathrm{~m} / \mathrm{v})$. The cofactor thiamine pyrophosphate (TPP), and $\mathrm{MgCl}_{2}$ were added to the PDC aliquot to give a final concentration of 1 and $2.5 \mathrm{mM}$, respectively, and the $\mathrm{pH}$ was adjusted to 6 at $2-4{ }^{\circ} \mathrm{C}$ using $200 \mathrm{mM}$ MES. The PDC aliquots were centrifuged at $15000 \mathrm{~g}$ for $2 \mathrm{~min}$, and the supernatants were transferred to clean tubes. Reading was taken at $340 \mathrm{~nm}$. One unit of PDC activity was defined as oxidation of $1 \mu \mathrm{mol}$ of NADH per minute.

$\boldsymbol{\alpha}$-Amylase assay: Total amylase activity was measured following the method of Bernfeld (1955). Briefly, seedlings were harvested for enzyme extraction using $0.02 \mathrm{mM} \mathrm{NaH}_{2} \mathrm{PO}_{4}$ buffer at $\mathrm{pH} 6.9$ with $6 \mathrm{mM} \mathrm{NaCl}$ and the crude extract was used in the assay. Starch was first converted to maltose as catalyzed by amylase. The maltose produced was made to react with 3,5-dinitrosalicylic acid, forming a colored product with maximum absorption at $540 \mathrm{~nm}$ when reduced. The absorption values were read on a standard curve established with increasing amounts of maltose.

Phosphofructokinase assay: For the assay of phosphofructokinase, the extraction methods described above for ADH and PDC were followed. Activity of phosphofructokinase was assessed spectrophotometrically by coupling the enzyme with aldolase, triosephosphate isomerase, and glycerol-3-phosphate dehydrogenase. A reaction mixture contained 0.1 M HEPES-KOH, $\mathrm{pH}$ 7.9, $2 \mathrm{mM} \mathrm{MgCl}_{2}, 0.15 \mathrm{mM} \mathrm{NADH}, 7.5 \mathrm{mM}$ fructose-6phosphate, $1 \mathrm{U}$ of aldolase, $1 \mathrm{U}$ of triosephosphate isomerase, and $1 \mathrm{U}$ of glycerol-3-phosphate dehydrogenase. The reaction was started by addition of $2.5 \mathrm{mMATP}$. The activity was assayed at $30{ }^{\circ} \mathrm{C}$. One unit of phosphofructokinase activity was the amount of the enzyme that oxidized $1.0 \mu \mathrm{mol}$ of $\mathrm{NADH}$ per minute.

Isolation of total RNA and cDNA synthesis: Total RNA was isolated from seeds collected at different time points using pure link reagent (Invitrogen, Carlsbad, USA) following the manufacturer's instructions. Purification of RNA was carried out using DNaseI (Sigma Aldrich, Saint Louis, USA) and the RNA concentration was determined using Nanodrop 2000 (Thermo Fisher Scientific, Wilminton, USA). The integrity of the RNA samples was analyzed using $1.5 \%(\mathrm{~m} / \mathrm{v})$ agarose gel electrophoresis stained with ethidium bromide. The RNA $(1 \mu \mathrm{g})$ was used for cDNA synthesis using the Prime Script $R T$ reagent kit (Takara, Tokyo, Japan) following the manufacturer's guidelines.
Quantitative real-time PCR reactions were performed on an Applied Biosystem (Foster City, USA) equipment using SYBR Premix Ex Taq (Takara). PCR conditions were optimized based on primer efficiency. Briefly, a $10 \mathrm{~mm}^{3}$ of reaction mixture consisted of $5 \mathrm{~mm}^{3}$ of SYBR Premix Ex Taq, $0.2 \mathrm{~mm}^{3}$ of $R O X$ dye, $2 \mathrm{~mm}^{3}$ of cDNA (50 ng; 1:20 dilution) and $1.8 \mathrm{~mm}^{3}$ of nuclease-free water (Ambion, USA) using three different primer concentrations, along with negative control (without cDNA). The following thermal cycle was used for all PCR reactions: $95{ }^{\circ} \mathrm{C}$ for $30 \mathrm{~s}$, followed by 40 cycles at $95^{\circ} \mathrm{C}$ for $5 \mathrm{~s}$ and $60^{\circ} \mathrm{C}$ for $30 \mathrm{~s}$. After 40 cycles, the specificity of the amplicon was analyzed through the dissociation curve profile and agarose gel electrophoresis (2\%). GAPDH was used as a reference gene for gene expression study as described by Kumar et al. (2018). Each reaction was performed with three biological and three technical replications.

Statistical analysis: Trait differences were subjected to principal component analysis (PCA) and one-way factorial ANOVA, followed by the Tukey's HSD post hoc test $(P<0.05)$. All statistical analyses were performed using statistical package XLSTAT (https://www.xlstat.com).

\section{Results}

To identify hypoxia tolerant deep-water rice germplasm as a potential donor, deepwater rice genotypes were screened under hypoxic condition in fine soil (collected from Assam rice field) to assess their germination and survival potential under flooding. In all, 160 genotypes from North East India province of Assam were screened for tolerance to flooding. Extensive variation was observed with respect to the ability of seeds to germinate and grow under hypoxia and reached the water surface when subjected to flooding during germination (Fig. 2 Suppl.). In our study, only one genotype performed exceptionally well in regard to the set parameters and even outperformed the positive check KHO (Fig. 2 Suppl.). The selected genotype Rangadhar Kekua Bao (henceforth referred to as RKB) exhibited

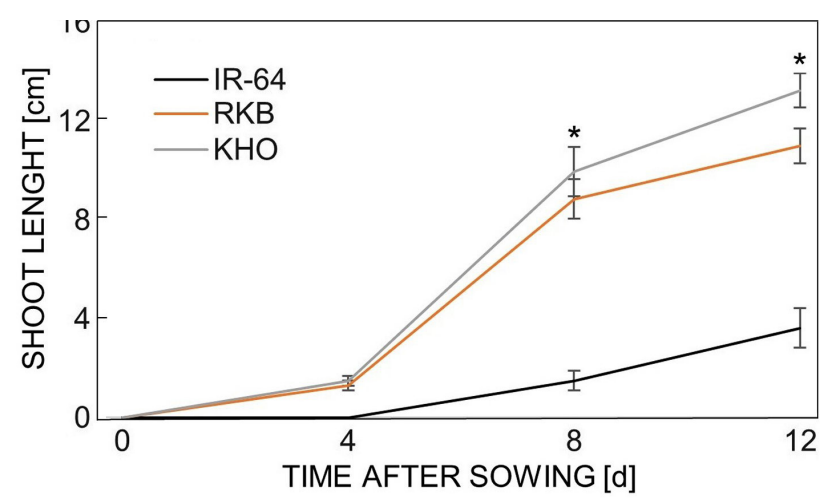

Fig. 1. The shoot length of rice seedling genotypes grown under anaerobic conditions caused by submergence. Means \pm SDs of two separate experiments with at least 30 seedlings of each genotype. Statistical significance $(*)$ set at $P<0.05$; one-way ANOVA, followed by the Tukey's honestly significant difference (HSD) post hoc test. 


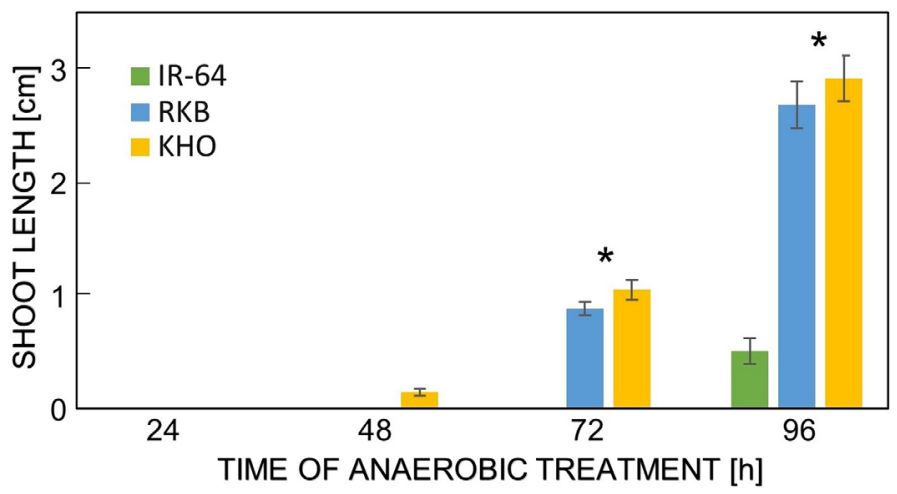

Fig. 2. Changes in shoot length of rice seedlings caused by anaerobic treatment. Means \pm SDs of two separate experiments with at least 30 seedlings of each genotype. Statistical significance (*) set at $P<0.05$; one-way ANOVA, followed by the Tukey's honestly significant difference (HSD) post hoc test.
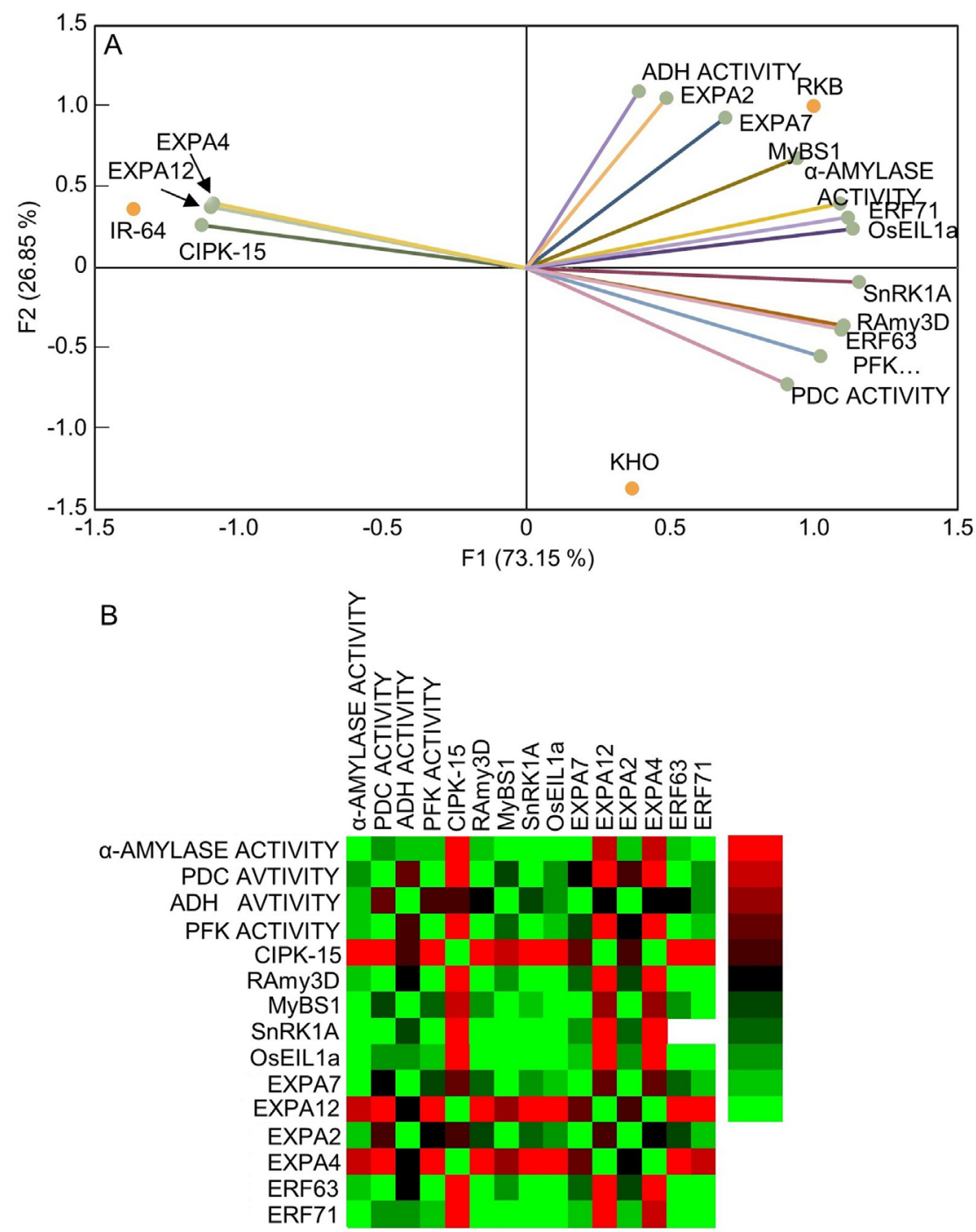

Fig. 3. A - Principal component analysis for anaerobic germination traits. Principal components (PC) of three genotypes (two tolerant and one sensitive) and anaerobic responsive genes and enzymes for anaerobic germination. Each point represents individual genotype colored according to its percentage contribution to the component (variable $\cos 2 \times 100 /$ component $\cos 2$ ). The color and length of arrows are proportional to the contribution to the component. $B$ - A correlation matrix between anaerobic responsive genes and enzymes. Positive correlations are displayed in green, and negative in red. Color intensity and square size are proportional to the correlation coefficients. 


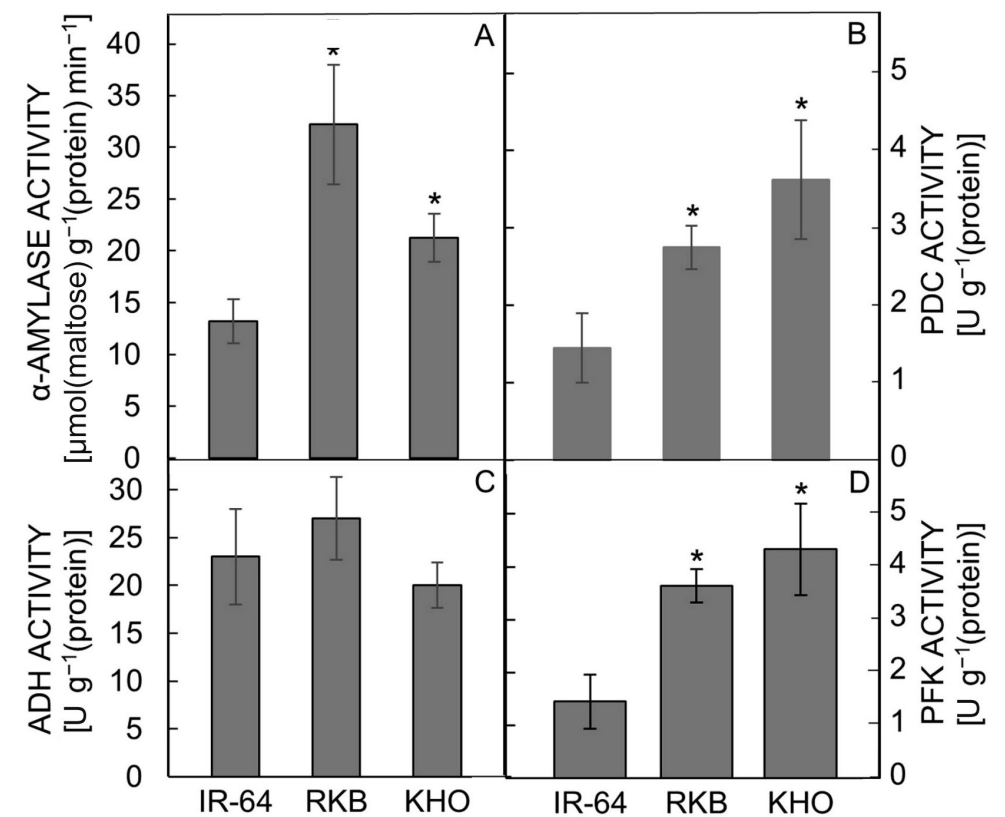

Fig. 4. Activities of enzymes in both tolerant (RKB and KHO) and sensitive (IR-64) rice genotypes under anaerobic conditions caused by submergence for $4 \mathrm{~d}$. PDC - pyruvate decarboxylase, ADH - alcohol dehydrogenase, PFK - phosphofructokinase, U - unit, defined for each enzyme in Materials and methods. Means \pm SDs of two biologically independent experiments, each with duplicate samples. Statistical significance (*) set at $P<0.05$; one-way ANOVA, followed by the Tukey's honestly significant difference (HSD) post hoc test.

$72 \%$ germination and final establishment which was higher than the tolerant KhaoHlanOn (KHO) and Ma Zhan (Red) genotypes that showed 45 and $30 \%$ germination, respectively, under flooding (Fig. 2 Suppl.). In spite of higher germination rate of RKB, the time of coleoptile emergence was delayed by $2 \mathrm{~d}$ compared to that of $\mathrm{KHO}$ (Fig. 1). Similar coleoptile growth kinetics of tolerant genotypes KHO and RKB were observed under flooded conditions when tested up to $4 \mathrm{~d}$ after sowing in controlled incubator and grown under dark, a conditions under which biochemical and molecular analyses were to be carried out
(Fig. 2). This can be seen from the PCA (Fig. 3A). IR-64, a sensitive genotype, is placed on the opposite side of the tolerant genotype RKB in the PCA plot. In this analysis, also RKB and IR64 were found on opposite sides of the first PC dimension. KHO, which was a positive control, was positively correlated to RKB (Fig. $3 A, B$ ) and RQ value and enzymes activities are listed in Table 1 Suppl. Anaerobic responsive genes and enzymes classified in the first component of PCA indicate their contribution in conferring tolerance to hypoxia during anaerobic germination of the tolerant rice germplasm RKB. These studies suggest that

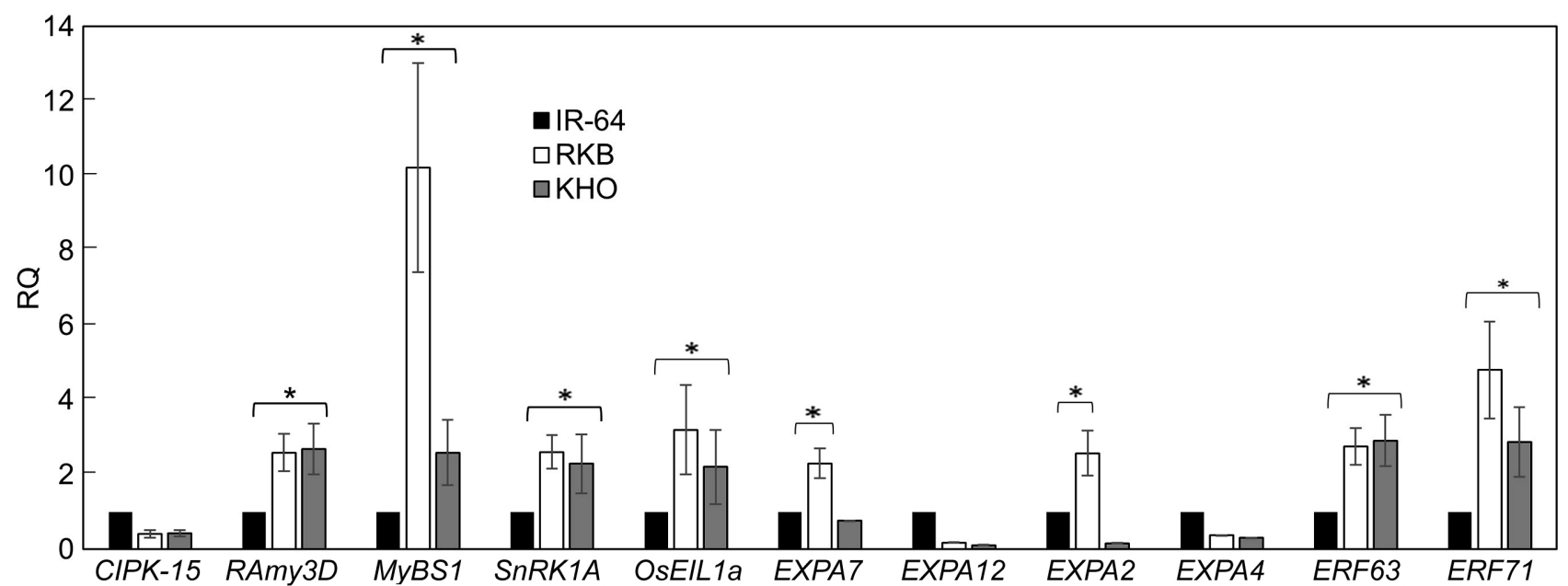

Fig. 5. Transcriptions of structural genes involved in anaerobic germination signaling. Relative quantification (RQ) of calcineurin $B$-like protein-like protein kinase 15 (CIPK15), sucrose nonfermenting 1 related protein kinase (SnRK1A), myeloblastosis related protein S1 (MYBS1), rice amylase $3 D$ (Ramy3D), ethylene insensitive 3-like la (OsEIL1a); transcription factors - ethylene responce factors 63 and 71 (ERF71, ERF63); proteins - expansins A2, A4, A7, and A12 (EXPA2, EXPA4, EXPA7, EXPA12). Means \pm SDs, $n=3$, statistical significance $\left(^{*}\right)$ set at $P<0.05$; one-way ANOVA, followed by the Tukey's honestly significant difference (HSD) post hoc test. 
the tolerant phenotype underpins the presence of a robust regulatory mechanism at the molecular level. Our interest was to confirm the concomitant perturbation in transcript accumulation of hypoxia responsive genes involved in $\mathrm{O}_{2}$ deficiency/hypoxia signaling.

This study confirmed the presence of TPP7 gene in RKB while deletion of AG1 QTL $(20.8 \mathrm{~kb})$ region in IR-64 (Fig. 3 Suppl.) using the flanking region primers (Kretzschmar et al. 2015) and gene specific primer. Moreover, the transcript accumulation in RKB at $96 \mathrm{~h}$ was 4.23-fold higher in the hypoxic conditions when compared to RKB samples collected under control conditions (Fig. Suppl. 3D).

Higher survival percentage of hypoxia tolerant germplasm RKB was associated with higher activity of enzymes related to starch catabolism and fermentation. The similar starch content in RKB (82\%), KHO (89\%) and IR-64 (85\%) and no marked changes in $\alpha$-amylase activity was observed up to $2 \mathrm{~d}$ after submergence (DAS) in both tolerant and intolerant genotypes while at 3 and $4 \mathrm{DAS}$, the $\alpha$-amylase activity was significantly higher in RKB compared to both KHO and IR-64 (Fig. 4). The fermentative metabolisms during the coleoptile elongation in rice mainly involved $\mathrm{PDC}$ and $\mathrm{ADH}$. The activity of PDC was significantly higher in RKB and KHO compared to IR-64. The ADH activity was higher in RKB when compared with IR-64 and KHO (Fig. 4C). An induction of PDC activity was detected at 4 DAS of anoxia (Fig. $4 B$ ). The activity of phosphofruktokinase was significantly higher in RKB and KHO as compared to IR-64 (Fig. 4 D).

Germination of seeds under hypoxia is primarily triggered by $\mathrm{O}_{2}$ deficiency. The CIPK 15 gene that acts as a central modulation of sugar and anoxia/hypoxia signals showed upregulated transcription under flood or hypoxia in tolerant rice genotypes including KHO (Kretzschmar et al. 2015). The CIPK15 is known to activate downstream protein kinase $S n R K 1 A$ in rice, considered as an energy sensor that regulates the sugar production through its action on $R A m y 3 D$. The transcription of $S n R K 1 A$ was significantly higher in both hypoxia tolerant genotypes RKB and KHO when compared to IR-64 (Fig. 5). SnRK1A is known to up-regulate as well as phosphorylate $M Y B S 1$ transcription factor. In our study, the transcription of MYBS1 was significantly higher in both tolerant genotypes compared to susceptible genotype (Fig. 5). The hypoxia-responsive amylase isoform $R A m y 3 D$ expressed in the rice scutellum has been implicated in a steady supply of carbohydrates essential for fast coleoptile growths under flood. Indeed, significantly higher accumulation of $R A m y 3 D$ transcripts in RKB and KHO genotypes compared with the IR46 suggested the higher conversion of starch into sugar by higher activity of $\alpha$-amylase under hypoxia observed in tolerant genotypes RKB and KHO (Figs. 4 and 5). Several group VII ERFs have been implicated in the induction of hypoxia-responsive genes both in rice as well as in Arabidopsis. All group VII ERFs of rice were studied in the current experiment but expression was low. However, the expression of the ERF71 was 4.83-fold and 2.28-fold higher in RKB and KHO, respectively, compared to IR64. The expression of ERF63 was 2.75-fold and 2.91-fold higher in RKB and KHO, respectively, compared to IR-64. Expansins family of genes was reported to be involved in elongation of coleoptile cells. More particularly, EXPA7 and EXPA2 genes were induced under anaerobic condition. The EXPA7 gene expression was 3.0-fold and 1.2-fold higher in RKB and KHO, respectively, compared to IR-64.

\section{Discussion}

Tolerance of rice under flooding by enhanced germination and early seedling growth is a prerequisite for the successful cultivation of rice in a region where flooding is a recurrent event. Emphasis on increasing the yield has led to widespread adoption of high yielding rice cultivars that lack the genetic makeup to withstand such unforeseen environmental stress. Although rice could tolerate flooding, its germination is limited to coleoptile elongation as root and primary leaf fails to develop in susceptible genotypes (Biswas and Yamauchi 1997). Considerable variation exists among rice genotypes in their ability to reach to atmospheric $\mathrm{O}_{2}$ through coleoptiles elongation during anoxia. This could be exploited to identify potential hypoxia-tolerant donors for introgression of a trait into high yielding rice cultivars through breeding. The deepwater rice genotypes cultivated in Assam, India, were thus screened for tolerance to hypoxia following their germination and early seedling vigor. Deepwater rice landraces could mitigate the rising level of floodwater through internode elongation (Vergara and Mazaredo 1979, Catling 1992, Nagai et al. 2012, Takeshi et al. 2018). Takeshi et al. (2018), reported that gibberellin biosynthesis gene, SD1 (semidwarf1) is responsible for submergence-induced internode elongation and that the $S D 1$ gene is transcriptionally activated by an ethyleneresponsive transcription factor, OsEIL1a. In the current experiment, the expression of OsEIL1a was significantly higher in RKB (3.2-fold) in comparisons with IR-64. The escape mechanism during flooding works only beyond 7-8 leaf developmental stage (Ayano et al. 2014) and may not have evolved to tolerate flood at the early seedling vigor stage per se. As evident from previous studies, anaerobic germination is a complex trait and performance of a tolerant genotype could vary depending on the oxygen deprivation (Miro and Ismail 2013). A sharp decline in germination ability of previously reported tolerant cv. Khaiyaan, as well as moderate performance of genotypes KHO and MZ Red under flooding in our screening, could be due to interaction with environmental factors like temperature and seedbed conditions besides others that are known to influence tolerance (Ella et al. 2010, 2011) and might limit the universality of protocol. The process of cell division and elongation is known to occur under hypoxia. However, while the ability of a cell to divide is determined by the period of submergence, which is around $48 \mathrm{~h}$ (Atwell et al. 1982) beyond that point, there would be energy bottlenecks due to a lack of oxygen (Magneschi and Perata 2009).Thus, faster elongation of coleoptile through cell division and elongation in hypoxia-tolerant genotype could involve high amylase activity making 
soluble sugar available for glycolysis and, subsequently, the fermentative metabolism as reported by Loreti et al. (2003). Higher transcription of Ramy $3 D$ in RKB compared to susceptible IR-64 genotype is understandable as this is a non-gibberellic pathway inducible form that is expressed in embryo and not in aleurone layer which lacks the enzyme due to blockage in oxidative biosynthesis (Ranjhan et al. 1992, Sugimoto et al. 1998). Indeed, no correlation between amylase activity in endosperm and coleoptiles under anoxia was found by Magneschi and Perata 2009, while high sugar content in embryo was found to be positively correlated to total amylolytic activities under anaerobic condition (Pompeiano et al. 2013). Rauf et al. 2019, has also reported that high Ramy $3 D$ mRNA accumulation in tolerant accessions suggests that major genes involved in anaerobic germination may vary depending on germplasm.

High amylase activity was primarily due to the binding of starvation or hypoxia-induced transcription factor MYBS1 that binds to TA Box of the sugar-responsive element (SRE) in the promoter of Ramy3D (Lu et al. 1998, Chen et al. 2002, 2006). In our study, we found higher transcript accumulation of MYBS1 in tolerant genotypes compared to susceptible genotype under hypoxia that indicated higher amylase mediated sugar utilization. Although transcript accumulation of SnRK1A was higher in tolerant RKB genotype, absence of any significant difference in KHO and susceptible IR-64 genotypes highlights the fact that rather than transcription regulation, sugar starvation or $\mathrm{O}_{2}$ deficiency influence post-transcriptional regulation of SnRK1A protein under hypoxia (Lee et al. 2009, Kretzschmar et al. 2015). SnRK1A modulates the activity of embryonic amylase in response to sugar-repression signals and maintains sugar homeostasis (Hardie and Sakamoto 2006, Rolland et al. 2006, Ghillebert et al. 2011, Robaglia et al. 2012). Besides, $S n R K 1 A$ is also responsible for activation and promotion of MYBS1 interaction with the Ramy3D promoter as is evident from the abolition of MYBS1 and Ramy3D expression under starvation in SnRK1 knockout rice transgenic plants (Chan et al. 1994, Lu et al. 2007). Thus, taken together, it could be inferred that $S n R K 1 A$ accumulation in tolerant genotypes ensures steady energy supply through the enhanced starch breakdown, facilitated by hypoxia-induced de-repression of glucose-inducible genes like Ramy3D. CBL-interacting protein kinases CIPK15 is known to be activated in response to $\mathrm{Ca}^{2+}$ released from mitochondria under low oxygen stress (Batistic and Kudla 2004, Luan 2009, Das and Pandey 2010). Rice CIPK15 mutant is unable to elongate coleoptiles only under water but it is able in the air (Lee et al. 2009). Contrary to this, low transcript accumulation of CIPK15 in RKB genotype under hypoxia might indicate a redundant signaling component in the tolerant genotypes. Besides, CIPK15 is known to regulate the accumulation of SnRK1A and Ramy3D proteins in response to sugar starvation (Lee et al. 2009). It has been reported that enhanced starch degradation observed in hypoxia-tolerant genotypes could be accomplished due to the removal of T6P (which acts as a sucrose sensor) via conversion to trehalose, a higher content of which would otherwise inhibit the $S n R K 1 A$ activation of amylase under hypoxia. Such results were also observed in the current investigation, i.e., presence of TPP7 in RKB and absence of it in IR-64. The presence of TPP7 in rice germplasms was associated with increased sink strength in elongating coleoptiles, and it helped a rapid escape of seedlings from submergence (Kretzschmar et al. 2015). Narsai et al. (2015) focused on the remarkable ability of rice seed to germinate and efficiently elongate their coleoptiles under extremely low $\mathrm{O}_{2}$ concentration. This includes the ability to rapidly switch to aerobic growth upon emergence from flood water. Yet, the presence of an additional factor in RKB having a crucial role may not far fetched as TPP7 gene, accounting for only $33.5 \%$ of the tolerance to hypoxia in KHO (Kretzschmar et al. 2015). The possibility of such factors is supported by the fact that T6P inhibition of $S n R K 1 A$ in leaves involves a yet-unidentified protein present only in young growing tissue in different species but not produced in mature tissue (Zhang et al. 2009). Such unknown factor or regulatory mechanism could thus contribute to species-specific as well as to withinspecies adaptive variation of complex traits (Wray et al. 2007). Kim and Reinke (2018), discovered three QTLs, associated with anaerobic germination tolerance. The percentage of variance ranges from 5.49 to $14.14 \%$ and maximum anaerobic germination of tolerant germplasms is approximately $50 \%$. In our study, we discovered that RKB has $72 \%$ germination rate under anaerobic conditions. Thus RKB can be a good material for breeders to discover new AG QTLs which could enhance the use of direct seeding methods and understand the genetic mechanisms controlling the germination and survival of plant under anaerobic conditions.

\section{Conclusions}

The physiological and molecular basis of rice germination and seedling growth under hypoxia were compared in different genotypes (RKB, IR-64, and KHO). The flooding tolerance of RKB was linked to high germination percentage, fast coleoptile elongation, and high survival rate under hypoxic condition. Even if the fastest coleoptile elongation was in $\mathrm{KHO}$ when submerged, its germination rate and survival was lesser than in RKB. Preliminary data showed that in RKB maintaining a steady supply of sugars due to activation of Ramy $3 D$ is the key for elongation and survival. The activities of fermentation enzymes (ADH and PDC) and starch degrading enzymes activities were higher in RKB in comparison with sensitive IR-64, except for ADH. Future research might lead to the identification of germplasm-specific additional novel components associated with anaerobic germination.

\section{References}

Angaji, S., Septiningsih, E.M., Mackill, D.J., Ismail, AM.: QTLs associated with tolerance of anaerobic condition during germination in rice (Oryza sativa L.). - Euphytica 172: 159168,2010 . 
Atwell, B.J., Greenway, H.: Carbohydrate metabolism of rice seedlings grown in oxygen-deficient solution. - J. exp. Bot. 38: 454-466, 1987.

Atwell, B. J., Waters, I., Greenway, H.: The effect of oxygen and turbulence on elonga-tion of submergence-tolerant and intolerant rice cultivars. - J. exp. Bot. 33: 1030-1044, 1982.

Ayano, M., Kani, T., Kojima, M., Sakakibara, H., Kitaoka, T., Kuroha, T., Angeles-Shim, R.B., Kitano, H., Nagai, K., Ashikari, M.: Gibberellin biosynthesis and signal transduction is essential for internode elongation in deepwater rice. - Plant Cell Environ. 37: 2313-2324, 2014.

Bailey-Serres, J., Chang, R.: Sensing and signalling in response to oxygen deprivation in plants and other organisms. - Ann. Bot. 96: 507-518, 2005.

Bailey-Serres, J., Voesenek, L.A.C.J.: Flooding stress: acclimations and genetic diversity. - Annu. Rev. Plant Biol. 59: 313-339, 2008.

Batistic, O., Kudla, J.: Integration and channeling of calcium signaling through the $\mathrm{CBL}$ calcium sensor/CIPK protein kinase network. - Planta 219: 915-924, 2004.

Bernfeld, P.: Amylases, alpha and beta. - Methods in Enzymol. 1: 149-152, 1955.

Biswas, J.K., Yamauchi, M.: Mechanism of seedling establishment of direct seeded rice (Oryza sativa L.) under lowland conditions. - Bot. Bull. Acad. sin. 38: 29-32, 1997.

Bradford, M.M.: A rapid and sensitive method for quantitation of microgram quantities of protein utilizing the principle of protein-dye binding. - Anal. Biochem. 72: 248-254, 1976.

Catling, D.: Rice in Deepwater. - Macmillan Press, London 1992.

Chan, M.T., Chao, Y.C., Yu, S.M.: Novel gene expression system for plant cells based on induction of alpha-amylase promoter by carbohydrate starvation. - J. biol. Chem. 269: 1763517641, 1994.

Chen, P.W., Chiang, C.M., Tseng, T.H., Yu, S.M.: Interaction between rice MYBGA and GA response element controls tissue-specific sugar sensitivity of $\alpha$-amylases genes. - Plant Cell. 18: 2326-2340, 2006.

Chen, P.W., Lu, C.A., Yu, T.S., Tseng, T.H., Wang, S.H., Yu, S.M.: Rice $\alpha$-amylase transcriptional enhancers direct multiple mode regulation of promoters in transgenic rice. - J. biol. Chem. 277: 13641-13649, 2002.

Coumou, D., Rahmstorf, S.: A decade of weather extremes. Nature Climate Change. 2: 491-496. 2012.

Das, R., Pandey, G K.: Expressional Analysis and Role of Calcium Regulated Kinases in Abiotic Stress Signaling. Current Genomics. 11(1): 2-13, 2010.

Ella, E.S., Dionisio-Sese, M.L., Ismail, A.M.: Propermanagement improves seedling survival and growth during early flooding in contrasting rice (Oryza sativa L.) genotypes. Crop Sci. 50: 1997-2008. 2010.

Ella, E.S., Dionisio-Sese, M.M., Ismail, AM.: Seed pre treatment in rice reduces dam age, enhances carbohydrate mobilization and improves emergence and seedling establishment under flooded conditions. - AoB Plants 2011:plr007, 2011.

Ella, E.S., Setter, T.L.: Importance of seed carbohydrates in rice seedling establishment under anoxia .- Acta Hort. 504: 209216, 1999.

Ella, E.S., Valdez, A.P., Reyes, R.V., Greenway, H., Setter, T.L.: Importance of several enzymes in limitation of alcoholic fermentation of rice under anoxia. - In: Proceedings of the $6^{\text {th }}$ Annual Meeting of the International Program on Rice Biotechnology. Pp. 1-5. 1993.

Fukao, T., Bailey-Serres, J.: Plant responses to hypoxia - is survival a balancing act? - Trends Plant Sci. 9: 449-456, 2004.

Ghillebert, R., Swinnen, E., Wen J., Vandesteene, L., Ramon, M., Norga, K., Rolland, F., Winderickx, J.: The AMPK/SNF1/
SnRK1 fuel gauge and energy regulator: structure, function, and regulation. - FEBS J. 27: 3978-3990, 2011.

Gibbs, D.J., Lee, SC., Isa, N.M., Gramuglia, S., Fukao, T., Bassel, G.W., Correia, CS., Corbineau, F., Theodoulou, F.L., BaileySerres, J.: Homeostatic response to hypoxia is regulated by the N-end rule pathway in plants. - Nature 479: 415-418, 2011.

Hardie, D.G., Sakamoto, K.: AMPK a key sensor of fuel and energy status in skeletal muscle. - Physiology (Bethesda). 21: 48-60, 2006.

Ismail, A.M., Ella, E.S., Vergara, G.V., Mackill, D.J.: Mechanisms associated with tolerance to flooding during germination and early seedling growth in rice (Oryza sativa). - Ann. Bot. 103: 197 209, 2009.

Jackson, M.B., Ram, P.C.: Physiological and molecular basis of susceptibility and tolerance of rice plants to complete submergence. - Ann. Bot. 91: 227-241, 2003.

Kim, S.M., Reinke, R.F.: Identification of QTLs for tolerance to hypoxia during germination in rice. - Euphytica 214: 160, 2018.

Kretzschmar, T., Pelayo, M.A.F., Trijatmiko, K.R., Gabunada, L.F., Alam, R., Jimenez, R., Mendioro, M.S., Slamet-Loedin, I.M., Sreenivasulu, N., Bailey-Serres, J., Ismail, A.M., Mackill, D.J., Septiningsih, E.M.: A trehalose-6-phosphate phosphatase enhances anaerobic germination tolerance in rice. - Natur. Plants 1: 1-5, 2015.

Kudahettige, N.P., Pucciariello, C., Parlanti, S., Alpi, A., Perata, P.: Regulatory interplay of the Sub1A and CIPK15 pathways in the regulation of $\alpha$-amylase production in flooded rice plants. - Plant Biol. 13: 611-619, 2010.

Kumar, D., Das, P.K., Sarmah, B.K.: Reference gene validation for normalization of RT-qPCR assay associated with germination and survival of rice under hypoxic condition. - J. appl. Genet. 59: 419-430, 2018.

Lee, K.W., Chen, P.W., Lu, C.A., Chen, S., Ho, T. H.D., Yu, S.M.: Coordinated responses to oxygen and sugar deficiency allow rice seedlings to tolerate flooding. - Sci. Signaling 2: ra61, 2009.

Licausi, F., Kosmacz, M., Weits, D.A., Giuntoli, B., Giorgi, F.M., Voesenek, L.A., Perata, P., Van, Dongen. J.T.: Oxygen sensing in plants is mediated by an $\mathrm{N}$-end rule pathway for protein destabilization. - Nature 479: 419-422, 2011.

Loreti, E., Yamaguchi, J., Alpi, A., Perata, P.: Sugar modulation of a-amylase genes under anoxia. - Ann. Bot. 91: 143-148, 2003.

Lowry, O.H., Nira, J., Rosebrough, A., Lewis, F., Rose J.R.: Protein measurement with the Folin phenol reagent. - J. biol. Chem. 193: 265-275, 1951.

Lu, C.A., Lim, E.K., Yu, S.M.: Sugar response sequence in the promoter of a rice a-amylase gene serves as a transcriptional enhancer. - J. biol. Chem. 273: 10120-10131, 1998.

Lu, CA., Lin, C.C., Lee, K.W., Chen, J.L., Huang, L.F., Ho, S.L.: The SnRK1A protein kinase plays a key role in sugar signalling during germination and seedling growth of rice. Plant Cell 19: 2484-2499, 2007.

Luan, S.: The CBL-CIPK network in plant calcium signaling. Trends Plant Sci. 14: 37-42, 2009.

Magneschi, L., Perata, P.: Rice germination and seedling growth in the absence of oxygen. - Ann. Bot. 103: 181-196, 2009.

Miro, B., Ismail, A M.: Tolerance of anaerobic conditions caused by flooding during germination and early growth in rice (Oryza sativa L.). - Front. Plant Sci. 4: 1-18, 2013.

Mustroph, A., Lee, S.C., Oosumi, T., Zanetti, ME., Yang, H., Ma, K., Yaghoubi-Masihi, A., Fukao, T., Bailey-Serres, J.: Cross-kingdom comparison of transcriptomic adjustments to low-oxygen stress highlights conserved and plant-specific responses. - Plant Physiol. 152: 1484-1500, 2010. 
Nagai, K., Kuroha, T., Ayano, M., Kurokawa, Y., Angeles-Shim, R. B., Shim, J. H., Ashikari, M.: Two novel QTLs regulate internode elongation in deepwater rice during the early vegetative stage. - Breed.Sci. 62: 178-185, 2012.

Narsai, R., Edwards, J.M., Robertsn, T.H., Whelan, J., Joss, G.H., Atwell B.J.: Mechanisms of growth and patterns of gene expression in oxygen-deprived rice coleoptiles. - Plant J. 82: 25- 40, 2015.

Perata, P., Geshi, N., Yamaguchi, J., Akazawa, T.: Effect of anoxia on the induction of a-amylase in cereal seeds. - Planta 191: 402-408, 1993.

Perata, P., Pozueta-Romero, J., Akazawa, T., Yamaguchi, J.: Effects of anoxia on starch breakdown in rice and wheat seeds. - Planta 188: 611-618, 1992.

Pompeiano, A., Francesca, F.: Amylolytic activity and carbohydrate levels in relation to coleoptile anoxic elongation in Oryza sativa genotypes. - J. Plant Res. 126: 787-794, 2013.

Quimio, C.A., Torrizo, L.B., Setter, T.L., Ellis, M., Grover, A., Abrigo, E.M., Peacock, W.J.: Enhancement of submergence tolerance in transgenic rice overproducing pyruvate decarboxylase. - J. Plant Physiol. 156: 516-521, 2000.

Ranjhan, S., Karrer, E.E., Rodriguez, R.L.: Localizing alphaamylase gene expression in germinated rice grains. - Plant Cell Physiol. 33: 73-79, 1992.

Rauf, M., Choi, Y M., Lee, S., Lee, M.C., Oh, S.: Evaluation of anaerobic germinability in various rice subpopulations: identifying genotypes suitable for direct-seeded rice cultivation. - Euphytica 215: 19, 2019.

Robaglia, C., Thomas, M., Meyer, C.: Sensing nutrient and energy status by SnRK1 and TOR kinases. - Curr. Opin. Plant Biol. 15: 301-307, 2012.

Rolland, F., Baena-Gonzalez, E., Sheen, J.: Sugar sensing and signalling in plants: conserved and novel mechanisms. Annu. Rev. Plant Bio. 57: 675-709, 2006.

Septiningsih, E.M., Ignacio, J.C.I., Sendon, P.M., Sanchez, D.L.,
Ismail, A.M., Mackill, D.J.: QTL mapping and confirmation for tolerance of anaerobic conditions during germination derived from the rice landrace Ma-Zhan Red. - Theor. appl. Genet. 126: 1357-1366, 2013.

Setter, T.L., Ellis, M., Laureles, C.V., Ella, E.S., Senadhira, D., Mishra, S.B., Sarkarung, S., Datta, S.: Physiology and genetics of submergence tolerance in rice. - Annu. Rev. Bot. 79: 67-77, 1997.

Sugimoto, N., Takeda, G., Nagato, Y., Yamguchi, J.: Temporal and spatial expression of the $\mathrm{OE}$ amylase gene during seed germination in rice and barley. - Plant Cell Physiol. 39: 323333, 1998.

Takeshi, K., Keisuke, N., Rice, G., Diane, R.W.: Ethylenegibberellin signaling underlies adaptation of rice to periodic flooding. - Science 361: 181-186, 2018.

Tuong, T.P., Pablico, P.P., Yamauchi, M., Confesor, R., Moody, K.: Increasing water productivity and weed suppression of wet-seeded rice: effect of water management and rice genotypes. - Exp. Agr. 36: 71-89, 2000.

Vergara, B.S., Mazaredo, A.: Using the new standard evaluation system to measuring elongation ability. - In: Proceedings of the 1978 International Deep Water Rice Workshop. Pp. 139142. International Rice Research Institute, Manila 1979.

Weits, D.A., Giuntoli, B., Kosmacz, M., Parlanti, S., Hubberten, H.M., Riegler, H., Hoefgen, R., Perata, P., Van Dongen, J.T., Licausi, F.: Plant cysteine oxidases control the oxygendependent branch of the N-end-rule pathway. - Natur. Commun. 5: 3425, 2014.

Wray, G.A.: The evolutionary significance of cis-regulatory mutations. - Natur. Rev. Genet. 8: 206-216, 2007.

Zhang, Y., Primavesi, LF., Jhurreea, D., Andralojc, P.J., Mitchell, R.A., Powers, S.J., Schluepmann, H., Delatte T., Wingler, A., Paul, M.J.: Inhibition of SNF1-related protein kinase1 activity and regulation of metabolic pathways bytrehalose-6phosphate. - Plant Physiol. 149: 1860-1871, 2009. 